\title{
Editorial
}

\section{Special issue: ISEA2017: Bio-Creation and Peace}

\section{Denise Doyle and Lynne Heller}

Welcome to this second issue of Virtual Creativity. This special issue gathers articles, art projects and visual essays, presented at ISEA2017 held in Manizales, Columbia, between the 11 and 18 June 2017. This was the first time that an ISEA conference has been held in 'a Spanish speaking country to recognize the bicultural heritage of a mega diverse country'. The hosts subtitled the event Bio-creation and Peace, inviting reflection 'on the role of art, design, science and technology, in the look for alternatives to respect this biodiversity, and pacific connivance between communities and environment'. The idea behind focusing on a special issue from such an interesting and diverse annual symposium was to help extend the reach of the symposium itself and to offer these journal contributors the opportunity to further develop their presentation papers, keynotes and art projects. The participants were selected because of their engagement with issues and interests in virtual, augmented or mixed reality.

In the first part of the issue, the four articles presented were written by ISEA2017 attendees who engaged with questions, issues and meditations on the virtual and the aesthetic inferences of that focus. The articles were written in response to art-making or cultural comment and/or production. 
Based on one of the Symposium Keynote presentations by Lance Putnam, the first article 'On space curves as a substrate for audiovisual composition' explores harmonic space curves as a basic, yet rich virtual material for the construction of audio-visual works. Putnam explains that artists now have unprecedented control over the use of mathematics in their artefacts and he presents his own work in utilizing space curves as a substrate for audio-visual synthesis and composition including a collaborative virtual reality artwork Mutator VR (with William Latham and Stephen Todd) recently exhibited at Ars Electronica. In 'Immersive dance and virtual realities' choreographer Johannes Birringer reflects on the mixed-reality experience of the latest instalment of the metakimosphere series of theatre/dance/VR installations, with a particular focus on the role of the virtual and of wearable VR headsets in the design scenography. Semi Ryu's article 'Avatar life-review in light of drama therapy' examines her ongoing avatar life-review projects in the light of drama therapy concepts and methods and explores a hybrid model of avatar/drama therapy in a virtually mediated environment. Finally in Taverna 'Translational Spaces: Virtual Narratives of Being \& Belonging' investigates processes of self-identification, social interaction and physical perception through a range of multimedia works. Taverna questions the notion of a homogeneous self within multiple physical and virtual realms and argues that the state of dislocation, familiar to those who have experienced cultural migration, has become more apparent as subjects now live as virtual immigrants within the realm of the digital.

The second part of the issue presents work in a different format, the visual essay, and ends with the ISEA2017 Symposium Report written by co-editor Lynne Heller. In 2016 British artists Vicky Isley and Paul Smith, collectively known as 
boredomresearch, were commissioned by the University of the West of Scotland (UWS) to produce a new digital artwork with the aim of supporting Paisley's bid to be City of Culture 2021. The result was a project entitled 'White Cart Loom' that reimagines the Paisley pattern as if it had grown in the shell of a freshwater pearl mussel and is presented here in their visual essay. 'White Cart Loom' uses real-time 3D software to generate animated, pearlescent forms that swim across the screen and pays homage to the biological diversity that is currently being lost on an unprecedented scale. The second visual essay is by Lynne Heller, where she presents her project Pillflower World, a multi-part project (2004-present) that explores how the omni-presence of pills and drugs in our culture is augmented by practices of selfmedication and pill swapping, evidence of a pill-popping society that is continually fed ubiquitous promotion and marketing advertisements that legitimate and foster our induced dependencies. The augmented reality app invites viewers to engage through a retina display iPad and the visual essay presented here documents the interactions through its various functions (grow, gather, play, dream, gift, dream) at the symposium. Finally, the symposium report by Lynne presents a personal account of the annual symposium that has been held every year since 1990 and offers a sense of the particular flavour of this very first symposium in South America.

We would like to thank all of the contributors to this issue and the journal reviewers who have enabled the work to be developed and expanded upon in such interesting ways and especially for those contributors responding so enthusiastically to the suggestion to participate in this special issue. 
Our next Volume 8 will again begin with a special issue, this time dedicated to submissions drawn from the 23rd International Conference on Virtual Systems and Multimedia (VSMM2017) held in Dublin, Ireland, from 31 October to 2 November 2017, a cross-disciplinary research and exchange in cutting-edge multimedia and virtual systems. The conference theme this year is Through the Looking Glass: Back to the Future of Virtual Reality, and the conference organizers suggest that

some 30 years after the dawn of VR, with a new boom in virtual devices, products and applications, it is an apt moment to look 'Back to the Future' and examine the potentials and pitfalls of VR, AR and 3D technologies.

We are very pleased to announce that this special issue will be co-edited by VSMM2017 conference Chair Professor Lizbeth Goodman and the VR pioneer Dr Jacquelyn Ford Morie, founder of All These Worlds Inc.

$<$ h1 $>$ Afterword

$<$ h2>Lynne Heller

I am grateful to Denise Doyle for including me as a co-editor for this issue of the journal. Over the past few years she has invited me to participate in various academic opportunities. These activities have been a source of both career and personal advancement. Thank you again for another enlightening and fulfilling experience.

\section{Contributor details}

With a background in Fine Art Painting and Digital Media, Denise Doyle is Senior Lecturer in Digital Media at the University of Wolverhampton, and Adjunct 
Professor of Virtual Worlds and Digital Practice at Ontario College of Art and Design University, Toronto. Denise is Editor-in-Chief of the Journal of Virtual Creativity. She has contributed research in the fields of art and technology, phenomenology, performance, video games, art and consciousness, virtual worlds, and digital arts practice through numerous book chapters and articles. She edited the artist led book New Opportunities for Artistic Practice in Virtual Worlds (2015) and sits on the editorial boards for the International Journal of Performance Art and Digital Media (Routledge) and the Journal of Gaming and Virtual Worlds, (Intellect).

Contact:

Denise Doyle

Faculty of Arts

University of Wolverhampton

WV1 1SB

UK

E-mail: D.Doyle@wlv.ac.uk 